\title{
Prospective multicentre study of the accuracy of surgery for horizontal strabismus
}

\author{
J R Lipton, H E Willshaw
}

\begin{abstract}
Eight centres throughout the United Kingdom cooperated with a prospective evaluation of the accuracy of surgery for horizontal strabismus. The eight centres were divided into four with a specialist interest in strabismus and four offering a general ophthalmic service. Each participating surgeon was asked to indicate the anticipated outcome of surgery and, thereafter, orthoptic examinations were made postoperatively to determine the actual outcome. Two hundred and five cases were included in the study and it is hoped the results will serve as useful guidelines for those departments wishing to undertake audit of their own strabismus surgery. There was no statistically significant difference in the accuracy of surgical alignment achieved by strabismus specialists and general ophthalmologists.
\end{abstract}

(Brf Ophthalmol 1995; 79: 10-11)

A substantial body of information exists demonstrating that accurate ocular alignment following strabismus surgery will lead to a better long term outcome with regard to both binocular function $^{12}$ and cosmesis. ${ }^{34}$

The accuracy of strabismus surgery is often assessed in terms of alignment within 10 prism dioptres of straight. ${ }^{5}$ However, a better measure of surgical accuracy would be the alignment in relation to the surgical goal, since in many instances the surgical objective is a small residual deviation rather than perfectly straight eyes.

Eight centres throughout the United Kingdom participated in a prospective multicentre study to address this issue. The results will, hopefully, provide basic data against which departmental audit results can be compared.

\section{Material and methods}

Eight centres agreed to contribute cases to a prospective study of the outcome of strabismus surgery. The centres included four with a specialist service in strabismus management and four offering a general ophthalmological service.

Consecutive patients were recruited over a 6 month period. Only patients having their first strabismus operation were included, and any patient who had surgery on the vertical recti or oblique muscles was excluded from the study.

One surgeon in each centre was asked to indicate, before surgery, the intended postoperative surgical alignment. This decision was based on the clinical judgment of the surgeon involved. Since only the accuracy of surgical alignment was being analysed, no attempt was made to standardise the surgical objectives or techniques among the participating surgeons.
Thereafter the details of each patient were recorded by an orthoptist at approximately 2 weeks, 2 months, and 6 months postoperatively. At each visit a full orthoptic assessment was carried out, including visual acuity, prism cover test at 6 metres and a third of a metre, and assessment of binocular single vision using tests appropriate for age. Other parameters were recorded by the orthoptist but have not been analysed in this study.

The accuracy of surgical alignment at 6 months after surgery was recorded as:

grade 1 - within plus or minus 5 prism dioptres of surgical goal

grade 2 - within plus or minus 10 prism dioptres of surgical goal

grade 3 - more than 10 prism dioptres from surgical goal

Results were analysed using Student's $t$ test to compare the accuracy of alignment achieved by specialist and non-specialist centres.

\section{Results}

One hundred and sixty four patients had horizontal muscle surgery for esotropia of various types, of which 125 were operated on by surgeons with a specialist strabismus service (group A) and 39 were operated on by surgeons offering a general ophthalmic service (group B). Because of the small numbers involved, statistical analyses were carried out on the group as a whole rather than on subtypes of esotropia.

Patients in group A had a mean preoperative deviation of 38 prism dioptres which, after surgery, was reduced to a mean of 12 prism dioptres. Group B patients had a mean preoperative deviation of 44 prism dioptres which, after surgery, was reduced to a mean of 14 prism dioptres.

Analysis of the two groups showed no other statistical difference when compared for age at presentation, incidence and degree of amblyopia, age at the time of surgery, and preoperative refractive error.

For patients in group A, 64\% achieved grade 1 alignment at 6 months postoperatively, a further $28 \%$ achieved grade 2 alignment, and $8 \%$ were more than 10 prism dioptres beyond the surgical goal.

For patients in group B the examination at 6 months showed $58 \%$ with grade 1 alignment, a further $31 \%$ with grade 2 , and $1 \%$ with grade 3 .

The difference between the groups does not reach statistical significance. The combined results for patients from both group $A$ and group B - that is, patients receiving their first operation for esotropia, showed that, at 6 months postoperatively, $62 \%$ aligned within plus or minus 5 prism dioptres of the surgical goal (grade 1) and 
Table 1 Surgical alignment achieved in 164 patients receiving first surgery for esotropia

\begin{tabular}{llll}
\hline Alignment & $\begin{array}{l}\text { Strabismus } \\
\text { specialists }\end{array}$ & $\begin{array}{l}\text { General } \\
\text { ophthalmology }\end{array}$ & Total group \\
\hline \pm 5 Dioptres & $64 \%(\mathrm{n}=80)$ & $56 \%(\mathrm{n}=22)$ & $62 \%(\mathrm{n}=102)$ \\
\pm 10 Dioptres & $92 \%(\mathrm{n}=115)$ & $89 \%(\mathrm{n}=35)$ & $91 \%(\mathrm{n}=150)$ \\
\hline
\end{tabular}

Table 2 Surgical alignment achieved in 41 patients receiving first surgery for esotropia

\begin{tabular}{llrr}
\hline Alignment & $\begin{array}{l}\text { Strabismus } \\
\text { specialists }\end{array}$ & $\begin{array}{l}\text { General } \\
\text { ophthalmology }\end{array}$ & Total group \\
\hline \pm 5 Dioptres & $64 \%(\mathrm{n}=16)$ & $75 \%(\mathrm{n}=12)$ & $\begin{array}{r}68 \%(\mathrm{n}=28) \\
\pm 10 \text { Dioptres }\end{array}$ \\
\hline
\end{tabular}

$91 \%$ within plus or minus 10 dioptres of the surgical goal (Table 1 ).

Further analysis of esotropic patients showed that those patients with an angle of deviation of 30 dioptres or less at presentation were more likely to achieve binocular single vision (BSV) $(p<0.05)$. There was a trend for those with grade 1 alignment to achieve BSV more commonly, but this did not reach statistical significance.

Forty one patients had horizontal muscle surgery for exotropia; 25 of these patients were operated on by surgeons with a specialist strabismus service (group C) and 16 by general ophthalmologists (group D).

Group C showed a mean preoperative deviation of 35 prism dioptres, while group D had a mean preoperative deviation of 33 prism dioptres. Postoperatively the mean deviation was reduced to 7 prism dioptres in each group. Again the two groups were matched in terms of the duration of strabismus, the incidence of amblyopia, and the age at both presentation and surgery.

In group C $64 \%$ of patients achieved grade 1 ocular alignment, with the remaining $36 \%$ achieving grade 2 . In group D $75 \%$ of patients achieved grade 1 alignment, and $25 \%$ grade 2 . Again the difference between the groups was not statistically significant. Taking the combined results of all patients receiving their first surgery for exotropia, $68 \%$ were found to be aligned within 5 dioptres of the surgical goal, and $100 \%$ were aligned within 10 dioptres (Table 2).

Analysis of the combined results with regard to age at presentation, preoperative angle, age at surgery, and presence of amblyopia was not statistically related to the accuracy of surgical alignment.

For the total group of exotropes, those with a preoperative angle of deviation of 30 prism dioptres or less were significantly more likely to achieve BSV postoperatively ( $\mathrm{p}<0.001)$.

When comparing the results for surgery on all types of strabismus, there was a trend for surgeons with a specialist strabismus service to obtain greater correction for any given surgical procedure, but this trend was not statistically significant. With primary horizontal muscle surgery for esotropia and exotropia no difference could be demonstrated between the accuracy of surgeons with a special interest in strabismus, and general ophthalmologists.

\section{Discussion}

Operations for strabismus are the second most common surgical procedures undertaken by ophthalmologists in the United Kingdom, and despite the trend to superspecialisation, it is probable that for the foreseeable future most such procedures will be undertaken by general ophthalmologists. It is reassuring, therefore, that no difference in accuracy of surgical alignment between generalists and specialists could be demonstrated.

The amount of surgery needed to correct a particular squint will vary according to the age of the child, the angle of deviation, ${ }^{6}$ and the nature of the squint. ${ }^{7}$ Other factors, including duration of strabismus, presence of amblyopia, presence of BSV, refractive error, etc may well be relevant, ${ }^{8}$ but appear to have a much smaller role in determining the correction achieved (unpublished data). The supervising surgeon must take all these factors into consideration when planning surgery, and also have a clear surgical objective in mind.

If we accept the accuracy needed for improved rates of BSV implicit in the report from Daiker et $a l^{9}$ then only $62 \%$ of esotropic patients achieved that goal. This report suggested a small, deliberate, overcorrection in the surgical management of selected cases of esotropia could greatly increase the incidence of postoperative attainment of BSV. Since more than 10 dioptres of overcorrection led to poorer results (as did any residual esotropia) this study seems to suggest that ideal alignment in such cases would be 5 dioptres of exo deviation with only plus or minus 5 dioptre variation being compatible with a good outcome. However, using the more usual criterion for surgical success - that is, alignment within plus or minus 10 dioptres of the surgical goal, then the surgeons in this study were 'successful' in $91 \%$ of esotropes, and $100 \%$ of exotropes.

It must be emphasised that these figures relate to the alignment achieved at 6 months after surgery, and there may well be a change in the alignment over longer follow up. However, the figure examined should relate to the accuracy of surgery, the issue which this study was designed to address.

Audit of clinical outcomes is a requirement of modern medical care, and some data with which to compare a department's surgical results should be helpful. We are grateful to those eight centre which cooperated with the study. They were: Birmingham Cardiff, Exeter, Hull, Leeds, London, Portsmouth, and Tayside.

1 Ing MR. Early surgical alignment for congenital esotropia. Ophthalmology 1983; 90: 132-5.

2 Keenan JM, Willshaw HE. Outcome of strabismus surgery in congenital esotropia. Brf Ophthalmol 1992; 76: 342-5.

3 Vasquez R, Calhoun JH, Harley RD. Development of monofixation syndrome in congenital esotropia. If Paediat Ophthalmol Strabismus 1981; 18: 42-4.

4 Willshaw HE, Keenen JM. Strabismus surgery in children: the prospects for binocular single vision. Eye 1991; 5: 338-43.

5 Scott WE, Reese PD, Hirsh CR, Flabetich CA. Surgery for large angle congenital esotropia. Arch Ophthalmol 1986; 104: $374-7$.

6 Willshaw HE, Mashoudi N, Powell S. Augmented medial rectus recession in the management of esotropia. Br F Ophthalmol 1986; 70: 840-3.

7 Hardesty HH, Boynton JR, Keenan JP. Treatment of intermittent exotropia. Arch Ophthalmol 1978; 96: 268-74.

8 Helveston EM. Accommodative esotropia. Trans New Orleans Acad Ophthalmol. New York: Raven Press, 1986: 111-8.

9 Daiker SR, Marsh AJ, Jampolsky A. Intentional surgical overcorrection of acquired esotropia. Arch Ophthalmol 1978; 96: 1848-52. 